\title{
Physical Activity Frequency of Special Olympics Athletes Aged 8-18 Across Economic Status
}

\author{
Kathryn Rozak', John T. Foley ${ }^{1}$, Cathy MacDonald ${ }^{1}$, Rebecca Bryan ${ }^{1}$, Meghann Lloyd ${ }^{2}$, \\ and Viviene Temple ${ }^{3}$
}

${ }^{1}$ State University of New York at Cortland, USA; ${ }^{2}$ Ontario University of Ontario Institute of Technology, Canada; ${ }^{3}$ University of Victoria, Canada

\begin{abstract}
The purpose of the study was to examine self-reported physical activity frequency of an international sample of children and youth aged 8-17 who participate in Special Olympics across economic status. A secondary aim was to determine if there was a difference between males and females in physical activity frequency across economic status. Data from 12,243 children and youth were available from the Special Olympics International Healthy Athletes Database after data cleaning ( 7819 male and 4424 female). Prevalence rates were calculated with confidence intervals for physical activity occurring less than three days per week, or three or more days per week across economic status of country (low; lower middle; upper middle and high income status). A series of Chi-square tests were used to determine the differences in physical activity frequency across economic status and gender. Overall, $65.4 \%$ of Special Olympics participants from low-income, $40.8 \%$ from lower-middle-income, $50.8 \%$ from uppermiddle-income, and $61.6 \%$ from high-income economies reported 3 or more days of physical activity per week. Additionally, male Special Olympic athletes tended to be more physically active than their female counterparts. Further research is needed to understand reasons for these differences and determine how to increase overall physical activity.
\end{abstract}

Keywords: Health Disparity, Special Olympics Healthy Athletes, Intellectual Disability

\section{Introduction}

Physical activity is important for children and adolescents in that it promotes mental and physical health benefits (McGarty, Penpraze, \& Melville, 2014). Research has shown that youth with intellectual disabilities (ID) have low levels of physical activity (Downs, Fairclough, Knowles, \& Boddy, 2016; Emerson, 2005; Finlayson, Turner, \& Granat, 2011; Foley, Bryan \& McCubbin, 2008; Stanish, Frey, \& Temple, 2006) when compared to typically developing peers. As youth move through adolescence and into adulthood, levels of physical activity decrease even further (Frey, Stanish, \& Temple, 2008; Pan, Liu, Chung, \& Hsu, 2014; Phillips \& Holland, 2011; Robertson et al., 2000; Temple \& Walkley, 2007; U. S. Department of Health and Human Services, 2000). This decrease in physical activity levels has been associated with an increased risk of secondary health impairments such as a decrease in health-related fitness, increased risk of obesity and increased depression (Johnson, 2009). At a minimum, youth with ID need to experience recommended levels of 60 minutes of daily physical activity to reap positive health benefits including increased aerobic capacity, gross motor function, and a better sense of self-concept (Tremblay et al., 2011).

Special Olympics International (SOI) is a nonprofit sports organization that provides training and sporting events year-round for children and adults with ID. SOI is a global endeavor that allows individuals with ID to participate in Olympic-type sports while offering the opportunity to further develop physically and socially (Special Olympics International, n.d.). Screening started in 1997, therefore two decades. SOI has been hosting free Healthy Athlete screenings at local, national and international competitions (Lloyd, Temple, \& Foley, 2012; Temple, Foley, \& Lloyd, 2014). Gathering of such data has been integral in the investigation of the health status of participating athletes and has allowed researchers to analyze this population in hopes of initiating interventions to increase healthy behaviors (Rintala, Temple, Lloyd, Faro, \& Foley, 2017). The purpose of this study was to examine the physical activity frequency of children and youth with ID who participate in Special Olympics across economic status. A secondary aim of this study was to determine if there is a significant difference 
in physical activity frequency between genders across economic status.

\section{Method}

\section{Participants}

This is a secondary analysis of physical activity status (less than 3 days, 3 or more days) in children and youth (8-17 years of age) participating in Special Olympics by country economic status. Data were extracted from participants of at least 8 years of age who had an ID (Special Olympics International, n.d.). For the purposes of participating in Special Olympics, a person is considered to have an ID if

a) they have a cognitive delay as determined by standardized measures such as an intelligence quotient (IQ),

b) a service agency or professional has determined the person has an ID in accordance with local policies, or

c) the person has functional limitations in both general learning and adaptive skills (Special Olympics incorporated, 2012).

\section{Data Source}

Healthy Athlete data are stored electronically with SOI and have been used in previous studies (Lloyd et al., 2012; Temple et al., 2014). For this study, data from 2004-2012 were derived from a subgroup (FUNfitness) of the SOI Healthy Athletes database. Variables included in the database were sex, date of birth, age, event type, location of event, country of participant, and self-reported frequency of physical activity which was dichotomized into "less than three days" or "three or more days". The original survey question asked "On AVERAGE, how many days each week do you do some physical activity?" Response options were: "No Regular Program," "1-2 days," "3-6 days," and "Every Day." Participants' data from 141 different countries were coded according to the criterion set forth by the World Bank for classifying economies (World Bank Country and Lending Groups, n.d). Categories were as follows: low income $(n=81)$, lower middle income $(n=1,061)$, upper middle income $(n=3,986)$ and high income $(n=7,115)$.

Athletes and/or guardians signed a medical release/ consent form to participate in Special Olympics prior to their respective event. Part of this document is consent for de-identified data to be used for research purposes to further examine the health of Special Olympic athletes. Research ethics approval was granted by the institution of the authors to conduct a secondary data analysis of the database.

\section{Data Cleaning and Analyses}

The data from Healthy Athletes screenings included 16,061 participants 8 to 17 years of age. Data cleaning procedures were as follows: (1) the identification of multiple entries for one individual and deletion of duplicate or redundant entries $(n=1,203)$. Sex, birthday and country were used to determine if data were duplicate entries; those participants with multiple entries over one or more years had only the most recent data retained for analysis. (2) Data with missing variables and with incomplete information such as gender, country or age were deleted. Prevalence rates were calculated with confidence intervals for physical activity occurring less than three days per week and for physical activity occurring three or more days per week across economic status of country (low; lower middle; upper middle and high income status). Chi squared analysis was used to examine differences in physical activity frequency across economic status of all participants as well as by male and female gender.

\section{Results}

A total of 12,243 participants were analyzed including 7819 males and 4424 females. The average age of both male and female participants was 14.3 years. Table 1 represents the number of participants within each category of economic status by physical activity frequency (less than three days per week/three or more days per week). The overall results indicate that there is a disparity in physical activity frequency among children and youth with ID across country economic status $\left(\chi^{2}(3)=237.36, p<0.01\right)$.

Over sixty percent of children and youth from countries of low and high economic status participated in at least 3 days of physical activity a week whereas those from lower middle and upper middle income countries were less active. No significant difference was found between low income and high income countries $\left(\chi^{2}=0.49, p=0.48\right)$, but there were significant differences between low income and lower middle income countries $\left(\chi^{2}(1)=18.66, p<0.01\right)$ and low income and upper middle income countries $\left(\chi^{2}(1)=6.8, p<0.01\right)$. Significant differences were also seen between lower middle and upper middle countries $\left(\chi^{2}(1)=33.15, p<0.01\right)$ and lower middle and high income countries $\left(\chi^{2}(1)=164.89, p<0.01\right)$, 
Table 1

Physical Activity Frequency of Special Olympics Participants by economic status

\begin{tabular}{ccccc}
\hline & \multicolumn{4}{c}{ Percent of Youth $(95 \%$ confidence level) } \\
\cline { 2 - 5 } & $\begin{array}{c}\text { Low } \\
\text { Income }\end{array}$ & $\begin{array}{c}\text { Lower Middle } \\
\text { Income }\end{array}$ & $\begin{array}{c}\text { Upper Middle } \\
\text { Income }\end{array}$ & $\begin{array}{c}\text { High } \\
\text { Income }\end{array}$ \\
\hline $\begin{array}{c}\text { All }(N=12.243) \\
<3 \text { days }\end{array}$ & $(N=81)$ & $(N=1061)$ & $(N=3986)$ & $(N=7115)$ \\
$>3$ days & $34.6 \%(24.9-45.1)$ & $59.9 \%(56.2-62.1)$ & $49.2 \%(47.7-50.8)$ & $38.4 \%(37.3-39.5)$ \\
Male $(N=7819)$ & $65.4 \%(54.8-76.0)$ & $40.8 \%(37.8-43.8)$ & $50.7 \%(49.2-52.3)$ & $61.6 \%(60.5-62.7)$ \\
$<3$ days & $(N=53)$ & $(N=433)$ & $(N=2,023)$ & $(N=4,383)$ \\
$>3$ days & $31.7 \%(17-46.3)$ & $56.5 \%(52.7-60.4)$ & $48.4 \%(46.4-50.0)$ & $37.7 \%(36.2-39.1)$ \\
Female $(N=4424)$ & $68.3 \%(53.7-82.9)$ & $43.5 \%(39.6-47.3)$ & $51.6 \%(49.7-53.6)$ & $62.3 \%(60.9-63.8)$ \\
$<3$ days & $(N=28)$ & $(N=628)$ & $(N=1,963)$ & $(N=2,732)$ \\
$>3$ days & $37.5 \%(22.1-52.9)$ & $63.1 \%(58.6-67.7)$ & $50.9 \%(48.2-53.5)$ & $39.7 \%(37.8-41.6)$ \\
& $62.5 \%(47.1-77.9)$ & $36.9 \%(32.3-41.4)$ & $49.1 \%(46.5-51.8)$ & $60.3 \%(58.4-62.2)$ \\
\hline
\end{tabular}

as well as upper middle and high income countries $\left(\chi^{2}(1)=123.22, p<0.01\right)$.

This study also examined the differences in physical activity frequency for males and females across economic status. Overall, males tended to be more active across economic status $\left(\chi^{2}(1)=123.22\right.$, $p<0.01)$. When broken down by economic status, males had significantly higher reported physical activity frequency than females in the lower middle income $\left(\chi^{2}(1)=11.75, p<0.01\right)$, upper middle income $\left(\chi^{2}(1)=15.36, p<0.01\right)$; high income countries $\left(\chi^{2}(1)=10.95, p<0.01\right)$.

\section{Discussion}

The aim of this study was to determine if physical activity frequency of children and youth with ID varied across country economic status. Results from our study showed that individuals from high income countries are physically active more often than those from lower middle and upper middle income countries. Additionally, individuals from low income countries were more physically active than lower middle and upper middle-income countries. Lower income areas are experiencing an influx of modern advancements such as television and computers and increased access to car travel. As such amenities gain favorability, the more traditional experiences of farming, walking to or from school, and completing household chores decrease. With a growing focus on such activities, physical activity frequency is likely to continue to decrease and the risk of overweight or obesity may increase.
Given the recent findings showing differences in BMI by region and economic status among youth with ID (Lloyd et al., 2012; Lloyd, Foley, \& Temple, 2014), it is important to understand if variations in physical activity also exist across economic status. This study highlights physical activity frequency of individuals with ID according to economic status. In general, physical activity frequency as it relates to individuals according to economic status is an understudied topic. While little is known about the relation between country income status and physical activity, there is evidence of the association between that individual economic level and physical activity. Stalsberg and Pedersen (2010) found that higher social economic status (SES) was associated with higher frequency of physical activity compared to those with lower SES. Special Olympics provides such opportunity to be physically active and engaged for those with ID, often through school-provided programming, so this finding may not be representative of this population (Harada \& Siperstein, 2009).

Although the findings of this study show that physical activity levels for children and youth are lowest for lower middle and upper middle income areas, we also found that high income areas have some of the most physically active youth. Further, the small sample size from lower income countries indicate a level of caution should be used in interpreting and generalizing the results. Studies by Lloyd and her colleagues (2012; 2014) suggested that overweight/obesity rates for Special Olympics athletes of the same age (8-18) were greatest in countries of high economic status. Overall, $62 \%(n=4,383)$ of individuals from high income countries were physically active more than three days 
per week. These results show that physical activity cannot be the only contributing factor to increased levels of obesity. The findings of this study force us to look at the relationship between physical activity and levels of overweight/obesity among this population and consider other factors that may play a role such as nutrition and lifestyle. If there are limited opportunities for children or youth to be physically active within their communities, schools or neighborhoods, a risk they run is being physically inactive, which could be associated with a decrease in strength, endurance, fitness, flexibility and increased risk of obesity and depression (Johnson, 2009).

A secondary aim of this study was to determine if there was a difference between males and females in physical activity frequency across economic status. Results found that females were less physically active than their male counterparts. This is consistent with literature regarding physical activity levels of males being higher regardless of whether they are typically developing (Colley et al., 2011; Troiano et al., 2008) or have ID (Lorenzi, Horvat, \& Pellegrini, 2000). Previous studies reported that males with ID were more physically active than females with ID, and that as individuals age, female activity decreases even further due to fewer opportunities to be active (Melville et al., 2008; Robertson et al., 2000; Bodde, Seo, Frey, Van Puymbroeck, \& Lohrmann, 2013). While this study looked at children and youth under the age of 18, Hilgenkamp, Reis, Wijck and Evenhuis (2012) found that female gender for adults is a predictor of low physical activity. Adult women with ID are less active and more likely to be obese and have a significantly higher BMI than males with ID (Bodde et al., 2013; Melville et al., 2008; Suzuki et al., 1991). Interventions need to be investigated to prevent gender from being a negative health predictor.

\section{Limitations}

All participants in this study were Special Olympics athletes. It is likely that these children and adolescents represent the higher end of the spectrum of physical activity level. It is also important to note that while the sample size for this study was relatively high $(n=12,243)$, when males and females were separated by physical activity frequency and economic status, the sample size of some cells, especially low and lower middle income countries $(n=81, n=1,061$, respectively), were very small (see Table 1 ). It is necessary that future research involving physical activity frequency of individuals with ID across economic status incorporate a wider range of individuals as well as, if possible, incorporating a larger sample size, especially from low and lower middle economic status countries.

Our study was limited to whether participants were active less than three days per week or active three or more days per week - there was no data on duration of the physical activity. It is also unknown what types of physical activities were performed during these days. While all participants have an ID as it is defined by SOI, it is unknown what the severity of ID level is among participants in this study. It has been noted that severity of ID is a limiting factor on physical activity levels for adults (Emerson, 2005). While this study looks at children up to age 18, studies by Emerson (2005), and Peterson, Janz and Lowe (2008) found that, in adults, as severity of ID increases, the level of physical activity decreases. Severity of ID may also have an influence on physical activity levels for children and adolescents. It is important that future research reports physical activity levels according to specific diagnoses. It is alarming to consider then, that if individuals with severe ID were involved, that physical activity levels could decrease even further for this population (Peterson et al., 2008).

\section{Implications for Future Research}

This research begins to establish a view of the relationship between physical activity frequency of children and youth across economic status. We were also able to determine that those in high income status countries had the highest level of physical activity; a somewhat unexpected finding given the knowledge that the highest levels of overweight and obesity are also found in such economic regions. This study concluded that economic status of a country also has an effect on the status of physical activity levels of males and females. Further research is necessary to continue to increase physical activity levels within the ID community, as they are at particular risk for secondary health issues that may develop as a result of inactivity. Although we have found that physical activity frequency was higher in low and high counties, and lower in lower middle and upper middle income countries, a better understanding of the relationship between physical activity and environmental influence will help researchers understand how to implement programming to increase physical activity for those with ID. Through sustained partnerships with Special Olympics and access to the Healthy Athlete 
database, researchers can continue to study the health outcomes of this population.

Physical activity is a contributing factor to a healthy lifestyle regardless of disability or economic status. It is important to create opportunities for physical activity for individuals with ID whether or not they are participants in Special Olympics. More research is needed to further analyze the relationship between physical activity frequency of individuals with ID and their economic status to determine what types of interventions may be necessary to prevent increases in overweight or obese children and youth and to promote physical activity and healthy eating behaviors to decrease secondary health conditions across the lifespan. Future research should explore strategies that could be used by SOI and other organizations to enhance physical activity among youth with ID.

\section{Perspective}

Results of the current study are the first to focus on physical activity frequency across economic status of country of youth with ID. Our results suggest that regardless of country economic status, many athletes are not active at least three days per week. And, consistent with previous research, male Special Olympics athletes were more physically active than females. Overall, the results are troubling as it may be expected that Special Olympics athletes represent a more physically active portion of the population of youth with ID.

\section{References}

Bodde, A. E., Seo, D., Frey, G. C., Van Puymbroeck, M., \& Lohrmann, D. K. (2013). Correlates of moderate-to-vigorous physical activity participation in adults with intellectual disabilities. Health Promotion Practice, 14(5), 663-670.

Colley, R. C., Garriguet, D., Janssen, I., Craig, C. L., Clarke, J. \& Tremblay, M. S. (2011). Physical activity of Canadian children and youth: accelerometer results from the 2007-2009 Canadian Health Measures Survey. Health Reports, 22(1), $15-23$.

Downs, S. J., Fairclough, S. J., Knowles, Z. R., \& Boddy, L. M. (2016). Physical activity patterns in youth with intellectual disabilities. Adapted Physical Activity Quarterly, 33(4), 374-390.

Emerson, E. (2005). Underweight, obesity and exercise among adults with intellectual disabilities in supported accommodation in Northern England. Journal of Intellectual Disability Research, 49, 134-143. doi:10.1111/j.1365-2788.2004.00617.x

Finlayson, J., Turner, A., \& Granat, M. H. (2011). Measuring the actual levels and patterns of physical activity/inactivity of adults with intellectual disabilities. Journal of Applied Research in Intellectual Disabilities, 24, 508-517.
Foley, J. T., Bryan, R. R., \& McCubbin, J. A. (2008). Daily physical activity levels of elementary school-aged children with and without mental retardation. Journal of Developmental and Physical Disabilities, 20, 365-378. doi:10.1007/ s10882-008-9103-y

Frey, G., Stanish, H., \& Temple, V. (2008). Physical activity of youth with intellectual disability: review and research agenda. Human Kinetics, 25, 95-117.

Harada, C. M., \& Siperstein, G. N. (2009). The sport experience of athletes with intellectual disabilities: a national survey of special olympic athletes and their families. Adapted Physical Activity Quarterly, 26, 68-85.

Hilgenkamp, T. I., Reis, D., Wijck, R. V., \& Evenhuis, H. M. (2012). Physical activity levels in older adults with intellectual disabilities are extremely low. Research in Developmental Disabilities, 33, 477-483. doi:10.1016/j.ridd.2011.10.011

Johnson, C. C. (2009). The benefits of physical activity for youth with developmental disabilities: A systematic review. American Journal of Health Promotion, 23, 157-167. doi:10.4278/ajhp.070930103

Lloyd, M., Foley, J. T., Temple, V. A. (2014). Body mass index of children and youth with an intellectual disability by country economic status. Preventive Medicine, 69, 197-201. doi: 10.1016/j.ypmed.2014.10.010

Lloyd, M., Temple, V. A., Foley, J. T. (2012). International BMI comparison of children and youth with intellectual disabilities participating in Special Olympics. Research in Developmental Disabilities, 33, 1708-1714. doi: 10.1016/j. ridd.2012.04.014

Lorenzi, D. G., Horvat, M., \& Pellegrini, A. D. (2000). Physical activity of children with and without mental retardation in inclusive recess settings. Education and Training in Mental Retardation and Developmental Disablities, 35, 160-167.

McGarty, A. M., Penpraze, V., \& Melville, C. A. (2014). Accelerometer use during field-based physical activity research in children and adolescents with intellectual disabilities: a systematic review. Research in Developmental Disabilities, 35, 973-981.

Melville, C. A., Cooper, S., Morrison, J., Allan, L., Smiley, E., $\&$ Williamson, A. (2008). The prevalence and determinants of obesity in adults with intellectual disabilities. Journal of Applied Research in Intellectual Disabilities, 21, 425-437. doi:10.1111/j.1468-3148.2007.00412.x

Pan, C. Y., Liu, C. W., Chung, I. C., \& Hsu, P. J. (2014). Physical activity levels of adolescents with and without intellectual disabilities during physical education and recess. Research in Developmental Disabilities, 36, 579-586. doi:10.1016/j. ridd.2014.10.042

Peterson, J. J., Janz, K. F., \& Lowe, J. B. (2008). Physical activity among adults with intellectual disabilities living in community settings. Preventive Medicine, 47(1), 101-106. doi:10.1016/j.ypmed.2008.01.007

Phillips, A. C., \& Holland, A. J. (2011). Assessment of Objectively Measured Physical Activity Levels in Individuals with Intellectual Disabilities with and without Down's Syndrome. PLOS One, 6(12). doi:10.1371/journal.pone.0028618

Rintala, P., Temple, V. A., Lloyd, M., Faro, C., \& Foley, J. T. (2017). Association of poverty and social exclusion with body mass index among Special Olympics athletes in Europe. International Journal of Public Health, 62(8), 921-928. doi: 10.1007/s00038-017-0982-5 
Robertson, J., Emerson, E., Gregory, N., Hatton, C., Turner, S., Kessissoglou, S., \& Hallam, A. (2000). Lifestyle related risk factors for poor health in residential settings for people with intellectual disabilities. Research in Developmental Disabilities, 21, 469-486. doi:10.1016/S0891-4222(00)00053-6

Special Olympics Incorporated. (2012). Special Olympics Official General Rules. Washington, DC.

Special Olympics International. (n.d.). Retrieved January 24, 2017, from http://www.specialolympics.org

Stalsberg, R., \& Pedersen, A. V. (2010). Effects of socioeconomic status on the physical activity in adolescents: a systematic review of the evidence. Scandinavian Journal of Medicine \& Science in Sports, 20(3), 368-383. doi:10.1111/j.1600-0838.2009.01047.x

Stanish, H. I., Frey, G.C. \& Temple, V. A., (2006). Healthpromoting physical activity of adults with mental retardation. Mental Retardation and Developmental Disabilities Research Reviews, 12, 13-21. doi:10.1002/mrdd.20090

Suzuki, M., Saitoh, S., Tasaki, Y., Shimomura, Y., Makishima, R., \& Hosoya, N. (1991). Nutritional status and daily physical activity of handicapped students in tokyo metropolitan schools for deaf, blind, mentally retarded, and physically handicapped individuals. American Journal of Clinical Nutrition, 54, 1101-1111.

Temple, V. A., Foley, J. T., \& Lloyd, M. (2014). Body mass index of adults with intellectual disability participating in Special Olympics by world region. Journal of Intellectual Disability, 58(3), 277-284.

Temple, V. A., \& Walkley, J. W. (2007). Perspectives of constraining and enabling factors for health-promoting physical activity by adults with intellectual disability. Journal of Intellectual \& Developmental Disability, 32(1), 28-38. https:// doi.org/10.1080/13668250701194034

Tremblay, M. S., Warburton, D. E., Janssen, I., Paterson, D. H., Latimer, A. E., Rhodes, R. E., ... Duggan, M. (2011). New Canadian physical activity guidelines. Applied Physiology, Nutrition, and Metabolism, 36(1), 36-46.

Troiano, R. P., Berrigan, D., Dodd, K. W., Masse, L .C., Tilert, T., \& McDowell, M. (2008). Physical activity in the United States measured by accelerometer. Medicine and Science in Sports and Exercise, 40(1), 181-188.

U. S. Department of Health and Human Services (2000). Healthy People 2010. Washington, DC: US Government Printing Office.

World Bank Country and Lending Groups (n.d.). Retrieved January 24, 2017, from http://data.worldbank.org/about/ country-classifications/country-and-lending-groups\#Low income

\section{Corresponding author}

John T. Foley

Email address | John.Foley@cortland.edu 